\title{
Sobre a novidade de Maquiavel: notas sobre a interpretação lefortiana do proêmio dos Discorsi
}

On the Novelty of Machiavelli: Notes on the Lefortian Interpretation of the Discorsi

Flávia Benevenuto

Universidade Federal de Alagoas | Alagoas | Brasil

\section{RESUMO}

A primeira empreitada assumida por Maquiavel em seus Discorsi é depreender a utilidade das coisas antigas e modernas. Essa via, que constitui parte de seu método, prevê a recorrência aos historiadores antigos e, ao mesmo tempo, à experiência das coisas modernas. As dificuldades dessa estratégia são perceptíveis já no proêmio dessa obra. Trata-se de investigar a complexidade desse método e procurar identificar seus limites a partir da perspectiva de Claude Lefort em Le travail de l'auvre: Machiavel.

\section{PALAVRAS-CHAVE}

Maquiavel; Discorsi; Claude Lefort.

\begin{abstract}
Machiavelli's first undertaking in his Discorsi is to grasp the utility of old and modern things. This path, which is part of his method, provides for the recurrence of ancient historians and, at the same time, the experience of modern things. The difficulties of this strategy are already perceptible in the beginning of this work. It is a question of investigating the complexity of this method and trying to identify its limits from the perspective of Claude Lefort in Le travail de l'ouvre: Machiavel.
\end{abstract}

\section{KEY WORDS}

Machiavelli; Discorsi; Claude Lefort. 
O legado dos escritos de Maquiavel é marcado por controvérsias e diferentes vertentes interpretativas. A variedade de interpretaçóes distintas e que, por vezes, partiam de argumentos opostos, geralmente tencionava o debate e acirrava posições. Durante muito tempo algumas dificuldades específicas de seus textos trouxeram embaraços àqueles que procuraram compreendê-las. Em parte porque era difícil encontrar uma solução definitiva a partir dos próprios textos e, em parte, porque já se havia avançado tanto na tomada de posicionamentos em relação ao texto que qualquer tentativa nova de interpretação que não se caracterizasse como eminentemente sólida era desconstruída pelas interpretações já postas. É nesse cenário que Claude Lefort inicia sua maior investigação. Le travail de l'œuvre: Machiavel caracteriza-se como uma obra extremamente densa e que ultrapassa o trabalho de interpretação. Mas, sobretudo, altera profundamente a forma como o legado de Maquiavel vinha sendo debatido. A partir da investida de Lefort problemas específicos e embaraçosos dos textos de Maquiavel, já longamente discutidos, foram elucidados de forma tão definitiva que desfizeram algumas tensões. Problemas que antes pareciam insolúveis ganharam soluções razoáveis. De tal modo que o peso da leitura lefortiana das obras de Maquiavel alterou o curso de seu legado e se inseriu efetivamente como leitura obrigatória para aqueles que estudam Maquiavel.

Algumas das dificuldades que aparecem nos textos de Maquiavel podem ser identificadas já no Proêmio dos Discursos sobre a primeira Década de Tito Livio. Esse pequeno trecho, recorrentemente caracterizado como enigmático, portava problemas significativos relativos ao método utilizado para a escrita do livro, aos objetivos do autor, seu título, e à forma como Maquiavel se inseria no contexto dos intelectuais de seu tempo. Em grande medida, fomentou posicionamentos opostos em relação aos propósitos dos escritos de Maquiavel e acabou se constituindo como um ponto de partida de grande parte das dissidências interpretativas que caracterizaram seu legado. Tendo em vista a profundidade do debate que se inicia a partir desse pequeno trecho, restringiremo-nos ao Proêmio dos Discursos sobre a primeira Década de Tito Livio de Maquiavel e às páginas de Claude Lefort que tratam especificamente desta passagem. Não se trata de investigar todos esses problemas nem de esgotar todas as possibilidades da interpretação que Claude Lefort apresenta dessa passagem, mas apenas de tomar por guia algumas das soluçōes apresentadas por ele para alguns dos problemas mais difíceis presentes nessa parte do texto de Maquiavel. Soluções essas que, tomadas em seu conjunto, alteraram a forma de se pensar as obras de Maquiavel e seus propósitos principais.

O Proêmio dos Discorsi é iniciado pela imagem das grandes navegações que marcaram o cinqueccento. Seus desafios imprevisíveis, perigos iminentes, sua trajetória por vezes rumo ao desconhecido - pavoroso e deslumbrante - e a própria novidade fascinante da empreitada constituem a imagem da aventura que 
Maquiavel aponta como inspiração do labor textual que ali ele inicia. Logo no início do Proêmio Maquiavel afirma que,

Assim mesmo, levado pelo natural desejo que em mim sempre houve de trabalhar, sem nenhuma hesitação, pelas coisas que me pareçam trazer benefícios comuns a todos, deliberei entrar por um caminho que, não tendo sido ainda trilhado por ninguém, se me trouxer enfados e dificuldades, também me poderá trazer alguma recompensa, por meio daqueles que considerarem com humanidade os objetivos deste meu labor (Machiavelli, 1997, p. 197)

A passagem conduz o leitor a percursos inéditos, e por si só provoca estranhamento, se considerado o título do texto. De que forma um texto de comentários das obras de Tito Lívio poderia se efetivar como uma novidade sem precedentes? Essa dificuldade inicial, no entanto, precede outra. A passagem, que anuncia uma grande novidade consequente da escolha de um percurso inédito, é acompanhada por um assunto de grande relevância em seu tempo, porém igualmente comum: a imagem dos antigos.

$\mathrm{Na}$ sequência da apresentação de seu trabalho Maquiavel versa sua pena ao encontro daquilo que se fazia mais caro aos seus contemporâneos: o conhecimento dos antigos. Principal tarefa dos intelectuais do Renascimento e expressão de seu tempo, a recuperação dos textos dos antigos manifesta-se claramente em todos os âmbitos da construção do saber renascentista, ainda, é claro, que não se restringissem a eles. Imediatamente pode-se perceber que o labor iniciado ali não se constrói a partir de uma única inspiração. Mas, ao prever como título um Comentário das obras de Tito Lívio, pretender uma grande novidade, e unir esse tema ao conhecimento dos antigos, Maquiavel parece colocar seu leitor diante de uma apresentação enigmática de sua proposta de trabalho. As linhas seguintes parecem trazer alguma luz ao confronto temático inicial. Nelas o autor questiona veementemente o método de recuperação dos antigos, o que certamente não passaria despercebido em seu tempo.

Logo após mencionar as homenagens prestadas à antiguidade — citando o exemplo de um fragmento de estátua comprado por alto preço para honrar também a casa daquele que o possui - Maquiavel inicia seus argumentos no intento de diferenciar o adorno de sua utilidade. Afirma que

Vendo, por outro lado, que as virtuosíssimas ações que as histórias nos mostram, ações realizadas por reinos e repúblicas antigas, por reis, comandantes, cidadãos, legisladores e outros que se fatigaram pela pátria são mais admiradas que imitadas; vendo, aliás, que a tais ações, em suas mínimas coisas, todos fogem, e que daquela antiga virtù não nos ficou 
nenhum sinal; em vista de tudo isso não posso deixar de admirar-me e condoer-me ao mesmo tempo (Machiavelli, 1997, pp. 197-198).

A passagem enuncia a crítica aos seus contemporâneos. Ela evidencia que se, a recuperação dos Antigos é uma característica inegável do período, seus objetivos e métodos não são consensuais. Aparentemente, ao fazer o mesmo que seus contemporâneos e partir dos Antigos, Maquiavel parece indicar diferenças e distanciamentos na forma de fazê-lo. Mas, ainda assim, seria essa a grande novidade que anunciara?

A sequência do prefácio não apresenta uma resposta rápida a essa pergunta. Antes de avançar na construção de algum argumento que pudesse elucidá-la, o autor procura demonstrar, através do direito e a medicina, o valioso ensinamento dos antigos. De acordo com ele, ao ver "que nos litígios civis que surgem entre os cidadãos, ou nas doenças nas quais os homens incorrem, sempre se pode recorrem a julgamentos e remédios que pelos antigos foram proferidos ou ordenados" (Ibid., p. 198). E, ao abordar cada metáfora separadamente, reafirma seu argumento segundo o qual os antigos constituem uma importante fonte de conhecimentos utilizados pelos modernos. No primeiro caso "porque as leis civis nada mais são que sentenças proferidas pelos antigos jurisconsultos, sentenças que, reduzidas a uma ordenação, ensinam nossos jurisconsultos a julgar" (Ibid.). O mesmo acontece no que diz respeito ao segundo caso. Assim, de acordo com Maquiavel, "a medicina ainda não vai além das experiências feitas pelos antigos médicos, que servem como fundamento aos juízos dos médicos do presente" (Ibid.). Ambas, ao invés de dissolver os questionamentos iniciais postos a partir do pressuposto da novidade, parecem intensificar a tensão sobre os propósitos do texto. E, inevitavelmente, os questionamentos iniciais permanecem.

De forma mais objetiva, seria possível conceber como inusitada a forma que Maquiavel abre seus Discorsi. Por um lado, faz críticas contundentes aos seus contemporâneos que, em sua perspectiva, não sabiam recorrer de forma eficaz aos ensinamentos dos Antigos e, por outro lado, compara a empreitada de seu texto com a da descoberta de novos mundos, reconhecendo-se em um caminho nunca antes trilhado. À primeira vista, as duas vias parecem seriamente incompatíveis: como imitar os Antigos poderia se configurar como novidade sem precedentes? De fato, em um momento em que todos volviam seus olhos ao passado, seria possível pactuar que os contemporâneos de Maquiavel realmente não sabiam se valer dos exemplos dos Antigos? E, por outro lado, se partimos do título, Discursos sobre a Primeira Década de Tito Livio, qual seria a novidade de um dos textos mais estudados em seu tempo? E mesmo que o texto de Lívio portasse uma novidade, Maquiavel estaria sugerindo que ela, até então, não havia sido vislumbrada por ninguém? Associada a essas dificuldades, o Proêmio do primeiro livro dos Discorsi 
porta outra, tão enigmática quantos as anteriores: o silêncio a respeito da obra anterior, $O$ Principe.

É, de fato, no sentido de solucionar os enigmas próprios não somente dessas primeiras páginas dos Discorsi, mas do próprio método de Maquiavel, que o trabalho investigativo de Claude Lefort se faz definitivo. Ele enfrentou essas dificuldades, trazendo para o debate sobre a obra de Maquiavel novas possibilidades de se perceber seus escritos. Em grande medida, contribuiu para desmistificar as primeiras impressões quase sempre ingênuas que se pode ter a partir das primeiras leituras das obras do autor. Essa é a primeira estratégia utilizada por Lefort, evidenciar os problemas de algumas leituras apressadas, muitas vezes recorrentes. Ao fazê-lo, pondera a expectativa mais imediata do Proêmio, aproximando-se do leitor menos cuidadoso do texto de Maquiavel. Além de dificuldades específicas das obras, Lefort introduz um dos temas mais complicados para os estudiosos dos textos de Maquiavel até então: a conciliação entre as suas obras.

Lefort parte do problema central do Proêmio, o objetivo da obra de Maquiavel. Para ele,

O Proêmio parece definir sem equivocidade o objetivo da obra: o autor quer convencer seus contemporâneos da necessidade de estender à política a imitação dos Antigos. Esta imitação, observa, é no presente assunto dos artistas, juristas, médicos, mas deixa indiferentes aqueles que têm o encargo da ação política; a admiração pela Antiguidade não engendra neles o desejo de buscar nestes modelos para as instituições e as condutas políticas (Lefort, 1972, p. 454).

É certo que ao questionar e atacar a atualidade pela sua incapacidade de vislumbrar nos grandes feitos passados possibilidades de soluçōes presentes certamente o texto de Maquiavel provocou muitos incômodos. Lefort sugere inicialmente que, para Maquiavel, enquanto os artistas, por exemplo, conseguiam se inspirar no passado trazendo para a arte de seu tempo elementos que a enobreciam, nos assuntos da cidade o mesmo não se sucedia. ${ }^{\mathrm{I}}$

Entretanto, essa compreensão inicial logo é questionada por Lefort, que acaba por questionar as intenções inicialmente apresentadas por Maquiavel e, partindo

I Sobre os temas recorrentes investigados no Renascimento, assim como para uma melhor compreensão das formas de recuperação dos textos antigos e principais distinçôes em relação ao período medieval, ver: BignotTo, Newton, Origens do Republicanismo Moderno; Cardoso, Sérgio (Org), Retorno ao Republicanismo; Garin, Eugenio, Moyen Âge et Renaissance; Kristeller, Paul Oskar, Tradição Clássica e Pensamento do Renascimento; Larivaille, Paul, A Itália no Tempo de Maquiavel; Pocock, J. G. A., The Machiavellian Moment; Reinhardt, Volker; Il Rinascimento in Italia; Skinner, Quentin. As Fundações do Pensamento Político Moderno. 
da solução que parecia posta de imediato, acaba radicalizando o problema:

Podemos duvidar de que o escritor julgue agora que as verdades da política estão depositadas em Tito Lívio. Ora, estas reticências se confirmam ao observar que, desde as primeiras linhas do Proêmio, reivindica a originalidade de seu empreendimento como se não tivesse precedente (Ibid., p. 455).

A análise feita por Lefort parte justamente desse estranhamento que as afirmaçôes de Maquiavel provocam em seus leitores de hoje e conduz sua argumentação diretamente rumo às intençōes do autor. Lefort considera atentamente o público do autor de Florença e o debate que lhe era próprio, mas evita precipitar conclusões sobre os mesmos. Pondera o seguinte:

Ora, enquanto acolhemos - nós leitores modernos - sua crítica sem preocupar-nos do lugar que ocupava Roma no pensamento dos florentinos, seremos propensos a aderir ingenuamente ao programa de um retorno à Antiguidade, a subscrever a oposição entre antigo e moderno, como se fosse nova, a acreditar que os exemplos romanos, efetivamente abandonados, fossem ser restaurados pelo autor. Mas se observarmos que se dirige a um público que mantém com a Antiguidade, com Roma, uma relação singular, que as marcas de sua grandeza são constantemente renovadas, devemos pesar melhor suas palavras (Ibid., p. 465).

De fato, a primeira empreitada assumida por Maquiavel é depreender, em seus escritos, a utilidade das coisas antigas e modernas. $\mathrm{O}$ método escolhido e empregado pelo autor de Florença o conduz a percorrer seus conhecimentos dos antigos - apreendidos especialmente a partir dos historiadores — e, da mesma forma, empregar toda a experiência adquirida na lida como secretário de sua cidade. Esse método, já utilizado no Príncipe, propiciaria encarar as questôes vigentes à luz dos ensinamentos dos antigos e parece resumir sua proposta.

Apesar de reconhecer o modo esplendoroso como os antigos abrilhantavam a arte de seus contemporâneos, o autor salienta a dificuldade de se reconhecer nas dificuldades políticas de seu tempo alguma inspiração da virtude de seus antepassados gloriosos. Muito embora admitisse que no direito e na medicina seus contemporâneos se valessem dos princípios utilizados desde a antiguidade, para Maquiavel, este hábito não podia ser generalizado a todas as áreas. Para ele, a exceção implicava justamente aos assuntos da vida pública: "No entanto, na ordenação das repúblicas, na manutenção dos estados, no governo dos reinos, na ordenação das milícias, na condução da guerra, no julgamento dos súditos, na ampliação dos impérios, não se vê príncipe ou república que recorra aos exemplos 
dos antigos" (Machiavelli, 1997, p. 198). Essa contraposição parece ser utilizada para evidenciar a fragilidade política de então, reconhecendo nela a origem dos problemas de seu tempo.

Porém, se considerarmos que os homens de ação em seu tempo voltavam seu olhos aos textos dos antigos promovendo um profícuo debate em torno de temas variados, mas que não necessariamente excluíam os que dizem respeito à vida pública, a crítica de Maquiavel ao seu tempo parece representar mais que uma mera crítica à falta de compreensão do passado. Lefort argumenta rumo ao ponto central do problema. De acordo com ele,

Sendo, pois, o objetivo despertar o desejo de imitação, o caminho que conduz a isto, pensamos, pode ser aberto por uma reaprendizagem da leitura; a isto os livros de Tito Lívio fornecerão suporte; tudo o que facilite seu entendimento, seguindo a comparação dos acontecimentos antigos e modernos, será destinado a apoiar a tarefa (Lefort, 1972, p. 455).

Inevitavelmente, esse método que pretende de certa maneira unir antigos e modernos para traçar as próximas linhas da história desemboca em uma crítica profunda ao seu tempo. Não somente pela fragilidade política que apresentava, mas, especialmente, pelo que Maquiavel considera ser a incapacidade de buscar soluçōes efetivas nos exemplos históricos dos antigos. A construção dessa crítica, no entanto, não se edifica no texto sem provocar incômodos ao seu leitor e constitui um objeto de análise que exige cuidado.

No intuito de investigar o assunto Lefort parece radicalizar o problema, conduzindo a questão da novidade de Maquiavel à da conciliação de suas obras. De acordo com ele, "se nos fiarmos nestas indicaçôes, o empreendimento dos Discorsi parecerá mais limitado que o do Príncipe" (Ibid.). Lefort aprofunda o questionamento inevitável entre a novidade proposta por Maquiavel, que parecia se fundar justamente sobre a recuperação dos antigos. "Como se acolheria sem reservas o apelo à imitação após descoberto a ruptura que consumava o Príncipe com os autores Antigos, notadamente com Aristóteles e Cícero?” (Ibid., pp. 455456). A partir daí Lefort conduz seus argumentos no sentido de encontrar uma solução para esse problema, pois a conciliação entre a novidade da empreitada maquiaveliana e os textos antigos torna-se ainda mais difícil, pelo menos à primeira vista, quando se considera também o conteúdo do Príncipe.

O ponto de partida da análise Lefortiana são as dedicatórias escritas por Maquiavel tanto para acompanhar $O$ Principe quanto para acompanhar seus Discorsi. Apesar de considerá-las objetos mais apropriados ao biógrafo, ainda assim, preservam elementos que não permitem ao leitor identificar uma mudança radical nas intenções de Maquiavel (Ibid., p. 457). De acordo com ele, no que diz 
respeito aos Discorsi, "é preciso convir que nem o interesse em relação ao governo do príncipe, nem a apreciação de sua política, nem a comparação das características da monarquia e da república, são eliminados" (Ibid.). Assim, ao perceber a continuidade desses elementos em ambas as obras de Maquiavel, Lefort direciona sua argumentação ao seu ponto central. Ele menciona capítulos do primeiro livro dos Discorsi em que, segundo Lefort, Maquiavel

Não se limita a comparar os méritos do príncipe com os do povo (como é o caso nos capítulos XXIX, LVI e LIX), mas analisa as situações que são enfrentadas igualmente por uma monarquia e uma república e que exigem do poder uma mesma estratégia (capítulos XXX, XXXII e LI); ou então define as condições requeridas para a implantação de um ou outro regime (Lefort, 1972, p. 458).

Para o autor, Maquiavel não escreve os Discorsi no intuito de sobrepor as repúblicas aos principados, mas de analisá-las igualmente evidenciando a capacidade de cada um desses regimes resistirem aos infortúnios, ampliar-se e durar. Se uma dessas formas de governo é superior a outra, isso poderia vir à tona no texto maquiaveliano como resultado da análise desses regimes, não como seu pressuposto.

Essa hipótese, no entanto, não é tão simples e Lefort enfrenta as dificuldades do texto de Maquiavel. Considera que

Ao louvar a virtude da imitação, ao sugerir que o mais novo coincide com o mais antigo, [Maquiavel] acalma a inquietação, finge reduzir seu projeto aos limites de uma restauração, mas provavelmente confirma assim o efeito do silêncio que marca o Príncipe, obra que não aproveitava a autoridade dos clássicos (Ibid., p. 458).

De fato, o sentido desse silêncio permanece e Lefort o mantém, provocando seu leitor e levando-o ao limite da crítica aos escritos de Maquiavel. Ao fazê-lo apresenta muito claramente uma possibilidade de solução:

Mas então volta com maior insistência a questão que toca à diferença dos dois livros. Se os ensinamentos do primeiro são retomados no segundo, qual é a virtude do começo? A afirmação de que os Discorsi se engajam numa via que jamais foi aberta, não pode conter uma justificação relativa? Apesar das aparências, a exploração da história antiga, e singularmente aquela de Roma e mais ainda a de Tito Lívio, não permitiria por acaso assegurar à fundação do Príncipe as bases que the faltavam? (Ibid., pp. 458-459).

Essa passagem nos conduz a pensar as obras de Maquiavel como complemen- 
tares. Os Discorsi perpassariam os mesmos temas do Príncipe, priorizando uma abordagem distinta. Abordagem esta que longe de se restringir a um comentário da obra de Tito Lívio, como sugere o título, desempenha um papel importante de crítica do historiador romano em questão, ultrapassando não somente os limites do comentário, como os da própria crítica. É justamente ao apontá-lo que Lefort consegue rever as hipóteses que havia identificado ao iniciar sua análise, propondo, consequentemente, uma revisão das leituras mais simplistas dos textos de Maquiavel. Sua estratégia argumentativa parece ser, inicialmente, apresentar ao leitor dos textos de Maquiavel a interpretação mais imediata e recorrente de seus textos e, aos poucos, apontar os problemas dessa leitura que creditavam ao título dos Discorsi um resumo de seu conteúdo e, especialmente, partia do pressuposto de que este texto rompia com o propósito do Príncipe, silenciando sobre o mesmo. $\mathrm{O}$ esforço de Lefort em analisar esse silêncio culmina em conclusão muito diversa. O confronto entre as hipóteses iniciais, que coincidiam com as leituras mais recorrentes dos textos de Maquiavel, e sua conclusão, é contundente.

Antes de chegarmos a ela, precisamos considerar que a chave de compreensão dessa conciliação entre as duas obras emerge da maneira como Lefort entende o conceito de imitação apresentado por Maquiavel. Lefort parte do princípio de que "nos equivocaríamos se não encontrássemos no apelo à imitação senão um artifício a aplacar a inquietação do leitor após a audaciosa afirmação da descoberta. Talvez desempenhe também esta função, mas Maquiavel engana somente quem quer se deixar enganar" (Lefort, 1972, pp. 463-464). Ao evidenciá-lo, Lefort resolve o problema tornado nítido que o uso que Maquiavel faz da retórica é o artifício de um plano de construção argumentativa complexo, mas que possui um objetivo preciso, relacionado à questão da imitação. De acordo com Lefort,

Desde o Proêmio faz uso do conceito de imitação que por sua própria natureza desperta a atenção; não se limita, após haver anunciado a via do novo, a sugerir que seria simples retorno ao antigo, mas faz entrever que este retorno implica uma elaboração da matéria até então identificada como a Antiguidade. Assim, introduz uma questão estranha, subordinando a exigência da imitação a do saber, a exigência do agir segundo a imagem do romano a de estabelecer o texto em que se torna legível sua figura (Lefort, 1972, p. 465).

Seguindo a argumentação de Lefort, $O$ Príncipe porta uma ideia nova da história, capaz de misturar os modelos e fatos antigos aos acontecimentos modernos. Ao fazê-lo Maquiavel não abandona, nos Discorsi, a proposta do Príncipe. Ao contrário, esforça-se em completá-la. Nas palavras de Lefort, 
Não cabe supor que os caminhos do Príncipe sejam abandonados. Antes devemos pensar que, para continuá-los, o escritor deve reconduzir seu empreendimento a uma origem que lhe faltava: uma origem, vislumbramos, que não poderia se localizar no plano da política, no da história ou no do discurso teórico, mas se dá em seu cruzamento, ao ser posto à prova na interrogação (Ibid.).

Lefort, assim, termina por encontrar uma solução razoável, capaz de conciliar de forma eficaz as obras de Maquiavel e, acima de tudo, de contribuir de forma efetiva para uma nova interpretação de seus textos. Até a publicação do seu Le travail de l'ouvre Machiavel havia dificuldades profundas do texto de Maquiavel ainda sem respostas satisfatórias. A conciliação das obras, especificamente, era um grande problema para os especialistas em Maquiavel e a investigação feita por Lefort mudou o rumo dos estudos versados sobre a obra do autor florentino.

Para encerrar seus argumentos Lefort volta a atenção de seu leitor para a forma peculiar como Maquiavel percebe Roma. De acordo com Lefort, "estaria mais justificado, com efeito, reivindicar a audácia de seu empreendimento se, fazendo de Roma a base de sua reflexão, sua escolha não estivesse dirigida unicamente pelas exigências da teoria, se atingisse com a imagem da Antiguidade e de Roma o coração das ilusões políticas de seu tempo" (Ibid., p. 466). É a partir das análises de Roma que Lefort pôde, de fato, mostrar a particularidade e originalidade das obras de Maquiavel. Se Roma e, mais especificamente, a República Romana era o grande paradigma do Renascimento, ele pôs-se a distingui-la de Veneza a partir de um modo muito original de compreendê-la, partindo, assim do lugar comum das análises de seu tempo e distanciando-se gradativamente até opor-se a seus contemporâneos em suas conclusōes. Ao evidenciá-lo Lefort não somente enfrentou as dificuldades do texto de Maquiavel chamando atenção para soluções muito razoáveis, mas não autoevidentes no texto, como evidenciou a novidade de Maquiavel. Ao debruçar-se sobre a obra do florentino encontrou elementos para pensar a França em que vivia. Por fim, Le travail de l'œuvre Machiavel e, de modo geral, o trabalho desenvolvido por Claude Lefort mudaram os rumos das leituras de Maquiavel e criaram novas condições de possibilidade para a compreensão não somente do texto do autor, mas das relaçôes sociais, das instituições, do espaço público, das relaçôes de poder, das formas de se pensar o político e a política. E é nisso que se constitui sua maior contribuição e, consequentemente, o mantém atual. 


\section{Referências}

Bignotto, Newton (200I). Origens do Republicanismo Moderno, Belo Horizonte: Editora UFMG.

Cardoso, Sérgio (2004) (Org.). Retorno ao Republicanismo, Belo Horizonte: Editora UFMG.

Garin, Eugenio (1989). Moyen Âge et Renaissance, trad. de l'italian par Claude Carne. Paris: Gallimard.

Kristeller, Paul. O. (1995). Tradição Clássica e Pensamento do Renascimento, trad. Artur Morão, Lisboa: Ediç̧ôes 70.

Larivaille, Paul (1988). A Itália no Tempo de Maquiavel, trad. Jonatas Batista Neto, São Paulo: Companhia das Letras/Círculo do Livro.

Lefort, Claude (1999). Desafios da Escrita Politica, trad. Eliana de Melo Souza, São Paulo: Discurso.

Lefort, Claude (1972). Le travail de l'auvre: Machiavel, Paris: Gallimard.

Machiavelli (1997). Opere. A cura di Conrado Vivanti, Torino: Einaudi-Gallimard, 3 vols.

Maquiavel (2007). Discursos a Primeira Década de Tito Livio, São Paulo: Martins Fontes.

Pocock, J. G. A. (1975). The Machiavellian Moment, Princeton: Princeton University Press.

Reinhardt, Volker (2004). Il Rinascimento in Italia, trad. Paolo Rubini. Bologna: Il Mulino.

Skinner, Quentin. As Fundações do Pensamento Político Moderno. Trad. Renato Janine Ribeiro e Laura Teixeira Motta. São Paulo: Companhia das Letras, 1996. 